\title{
The organiser and the MRCPsych Exam: the College's instruction versus Murphy's law
}

\author{
Walid Abdul-Hamid, Colm Cooney and George Stein
}

Murphy's law states that if something can go wrong it will go wrong. Our recent experience in organising the MRCPsych exam at two centres confirms the general validity of this aphorism. We wish to share our experiences with other senior registrars who may find themselves in a similar predicament.

Delegation is the key to success in life, medicine and psychiatry and the organisation of public examinations is no exception. The Chief Examiner delegates the task of organising the examination to the examinations department of the College. Officers of the College's examinations department then phone the various Trusts in the country to locate any Trust that still has hospital beds and is in the business of admitting patients. Once a suitable Trust is located the Clinical Tutor, or some other Consultant, is contacted and flattered with the offer of being called a 'Senior Organiser'. This title has been specially selected as it is known to dispel all feelings of being disorganised, impotent or chaotic which occasionally afflict the average NHS Consultant. Once the title of 'Senior Organiser' has been bestowed on the Consultant he/she summons a suitable senior registrar and asks/suggests/requests/demands/orders the senior registrar to become the organiser and the buck usually stops there. The senior registrar, especially if he/she is a good chap, accepts with alacrity for the following very good reasons.

(1) $\mathrm{He} /$ she would like to oblige the consultant.

(2) The administrattve experience may lead to a better reference.

(3) But deep down the true reason is that lurking in the unconscious is a powerful wish to prove that he/she is no longer a candidate but there is some other poor soul who must suffer the torture that the examiners are to mete out. He can rejoice (in secret of course) that there is no longer any need to remember exactly what Schneider's first rank symptoms are or whether Schneider had second or even third rank symptoms or whether Schneider was just a man who worked in a taxi rank.

\section{Before the exam}

The task of the Organiser involves most if not all the day to day running of the exam. Our experience suggests that there are three stages involved in the organisation.

\section{The planning stage}

The Organiser needs to read the College's instructions and procedures for the management of the examination. He needs to get hold of this document from the Senior Organiser as soon as it arrives because there is a serious risk that the Senior Organiser will (a) not read it, (b) lose it, (c) file it together with all the other official circulars he receives in which case both (a) and (b) will almost certainly apply.

\section{The appointment of personnel}

Secretary. The most important person in any psychiatric team is the secretary. She will need to book rooms at the hotel for the visiting examiners, ensure there is food and drink on the day of the exam and encourage the other secretaries to complete the summaries.

Stewards. Rebellious registrars or those still struggling with the exam may make unhappy stewards and exact their revenge by disappearing off to the ward, bank or canteen at critical moments. Overly kind stewards may not be helpful either because by being empathic (as all good psychiatrists should be) and over-identifying with the plight of the candidates they may commit treason and give the game away. The Organiser must firmly instruct stewards under his command (a) to remain at their posts all day, and (b) not to fraternise with the enemy.

Nurses. Nurses need to be appointed to look after the patients on the day of the examination. Patients might panic, or relapse, go to the pub, or worse still get better. An experienced nurse will ensure that none of these catastrophes occur. 


\section{Obtain support in the hospital}

It is helpful for the Organiser or Senior Organiser to write to the Chief Executive of the Trust informing him/her that the exam is being held because this may help to enhance the status of the hospital. The Chief Executtve will be pleased to receive such a letter because it will provide some reassurance that in spite of the last round of savage cuts and bed closures there is still some-one somewhere who seems to be connected with the monarchy who thinks that a reasonable standard of medicine is still being practised in the hospital. The assistance of more junior administrators can usually be enlisted by the use of key phrases such as 'liaison group' or 'committee meeting' but if all else fails the enticement of ' $a$ cup of tea' may work.

Junior doctors are needed to find suitable cases and write summaries. Unfortunately interesting and suitable cases tend to get better and choose to go home and spend time with their families. So case hunting must be left to the few weeks immediately prior to the exam.

\section{The exam}

The day of the exam is one of the longest in the lives of all the participants. The anxiety of the candidates is understandable, they can fail the exam which is not a nice thing to happen especially after having paid so much money. The examiners have to worry about whether they are letting someone loose on the public who is stupid, unsafe, dangerous or otherwise unsuitable. The Organiser has to assume the role of an airport flight control operator and ensure that the timetable provided by the College is strictly adhered to and that candidate and patient take off together at precise $\mathbf{5 0}$ minute intervals and this is followed by a safe landing of a candidate plus examiner session lasting for $\mathbf{3 0}$ minutes.

Five minutes before the end of this session the Organiser must knock on the door with his left hand, this knock serves four separate purposes: (1) it reminds the examiners that they only have a further five minutes in which to catch the candidate out; (2) it provides comfort to the candidate who know that they only have another five minutes in which they can be caught out; (3) in the afternoon this serves to wake the examiners up, and (4) for those organisers who still harbour negative feelings concerning their own exam or have repressed their negattve feelings they can give a particularly hard bang (but preferably they should refrain from breaking the door down).

The Organiser also needs to ensure that there is adequate tea, coffee and biscuits for all concerned. Unfortunately we only purchased one packet of biscuits to be shared by three groups of participants, the candidates, patients and examiners. It was only through sheer good fortune that our candidates were too nervous to eat, some of our patients had anorexda nervosa, and our examiners were portly middle-aged men preoccupied by the high prevalence of heart disease in portly middle-aged men, who had a penchant for celery sticks rather than chocolate biscuits. Had our examiners been young, hungry ambitious academics and our patients had bulimia instead of anorexia our incompetence in the catering department would have been fully exposed. On this basis we recommend that one packet of biscuits is insufficient and that in future the successful MRCPsych exam will be conducted with three packets of biscuits with one packet for each group of participants.

The College pays those who assist in the exams (nurses, stewards, secretaries etc.) a small sum of money and posts this to their home address. Unfortunately we only discovered this after the exam was over when every one had gone home and we had no idea where any-one lived. The day after the exam finished just about everybody went on holiday, went sick, or just disappeared off the face of the earth and it took weeks before we finally traced everyone's address. This task might have taken only a few minutes had the relevant information been collected on the day itself.

Few senior registrars seem to survive more than one or two spells as exam organisers; the reason for this rapid attrition is poorly understood and remains one of the mysteries of modern psychiatry. We urge funding bodies to take a more serious view of this matter and fund appropriate research. Possibly the shock to the system provokes a delayed form of post-traumatic stress disorder, but a more widely held view is that this is another presentation of the senior registrar burn-out syndrome.

*Walid Abdul-Hamid, Maudsley Hospital, Denmark Hill, London SE5 8AZ; Colm Cooney, St. Vincent's Hospital, Elm Park, Dublin 4, Ireland; and George Stein, Portnalls Unit, Farnborough Hospital, Orpington, Kent BR6 8ND

*Correspondence 